\title{
LA CERÁMICA CON DECORACIÓN GRABADA DE ÉPOCA TARTÉSICA: ESTADO ACTUAL DE LA CUESTIÓN
}

\section{TARTESSIAN POTTERY WITH ENGRAVED DECORATION: A DISCUSSION OF THE STATE OF THE ART}

\author{
por \\ MANUEl JosÉ CASADo ARIZA \\ Yo soy yo y mi circunstancia [...] \\ Ortega y Gasset. Meditaciones del Quijote.
}

RESUMEN Este trabajo pretende hacer un balance del papel que hasta ahora ha desempeñado la cerámica con decoración grabada dentro de los estudios sobre la cultura material tartésica. Trata por tanto de acercarse a un tipo cerámico de gran interés, pariente de las conocidas Tipo Carambolo, y cuyo estudio en profundidad podría aportar datos de relevancia para la comprensión de algunos aspectos materiales y culturales de las poblaciones que durante el Bronce Final/Hierro I poblaron el suroeste peninsular ibérico.

\begin{abstract}
The aim of this paper is to describe the role of the engraving technique decoration ceramic among the studies dealing with tartesic material culture. It is an attempt to give a closer point of view of a relevant ceramic type related with the Tipo Carambolo. A deep study of this ceramics might provide important data for the understunding of some material and cultural aspects of the people who lived in the southwest iberic peninsula.during the Final Bronce/ Iron I Age
\end{abstract}

Palabras claves Tartessos, Bronce Final/Hierro I, Cerámica con decoración grabada.

Key words Tartessos, Final Bronce/Iron I Age, engraving technique decoration ceramic.

La importante labor de investigación desarrollada por D. Manuel Pellicer en el ámbito de la protohistoria del suroeste peninsular y el mundo tartésico, es sólo una porción de una amplia carrera repleta de grandes aportaciones al desarrollo de la ciencia arqueológica en España. Sus estudios sobre cerámica, de gran profundidad y minuciosidad, han servido de ejemplo para posteriores generaciones de investigadores y han mostrado la importancia de adentrarse en el estudio de los materiales cerámicos como vía para comprender 
el comportamiento de las poblaciones que estudiamos. Como muestra de estos trabajos podemos citar dos ejemplos en los que D. Manuel Pellicer aborda el mundo cerámico tartésico, al que pertenece la especie que trataremos en este trabajo. Dichos estudios son "La cerámica a mano del Bronce Reciente y del Orientalizante en Andalucía Occidental”, publicado en la revista Habis y "El Bronce Reciente y los inicios del Hierro en Andalucía Occidental" en Tartessos Arqueología Protohistórica del Bajo Guadalquivir, obra coordinada por $\mathrm{M}^{\mathrm{a}}$ Eugenia Aubet. En ambos trabajos Pellicer menciona la cerámica grabada, abordándola a la vez que la incisa, como poco frecuente en los vasos finos y con los mismos motivos decorativos geométricos que las pintadas (Pellicer 1987-88:467 y Pellicer 1989:176). Estas decoraciones geométricas las hace arrancar desde el Calcolítico y posteriormente resurgen viéndose reforzadas por algunas importaciones de origen posiblemente geométrico egeo, teniendo su apogeo en la fase IIIA (750-650 a. C) (Pellicer 1989: 178), fase en la que encuadra también la cerámica grabada (Pellicer 1987-88: 467).

\section{APUNTES HISTORIOGRÁFICOS SOBRE LA ALFARERÍA TARTÉSICA}

La frase que abre este trabajo, aunque fue pensada para ser aplicada al hombre, ahora quizá pueda servirnos para ilustrar lo que sobre la vajilla tartésica se pretende decir en estas breves líneas introductorias. Decimos esto porque, adaptando la frase a nuestros intereses, también se podría haber dicho: "la cerámica es ella y sus circunstancias", es decir, una vasija es lo que es físicamente, el recipiente en sí mismo, con unas características tecnológicas y morfométricas determinadas, pero además es lo que las circunstancias del momento de su descubrimiento determinan que sea. La historia de las investigaciones está llena de casos en los que se cambia o matiza la personalidad, digamos, de tipos cerámicos al cambiar las circunstancias (enfoques teóricos, nuevos hállazgos, etc.) de la investigación. La familia de la cerámica tartésica ejemplifica perfectamente lo que aquí intentamos exponer.

De manera general se podría dividir el corpus vascular que se ha venido atribuyendo a la cultura tartésica en dos grandes grupos: uno el de las cerámicas finas con superficies, generalmente, bruñidas, al que pertenecen los célebres platos, cuencos y cazuelas con decoraciones geométricas bruñidas, pintadas y grabadas, y otro el de los recipientes de superficies toscas con decoraciones incisas y digitadas que han sido generalmente interpretados como recipientes de almacenamiento.

Las primeras opiniones que se arrojaron sobre algunos de los tipos vasculares a los que nos estamos refiriendo provienen de George Bonsor. Durante sus excavaciones en los Alcores de Carmona Bonsor encontró algunos fragmentos de cerámica bruñida, incisa y de impresiones digitales. Sobre las primeras opinaba que se trataba de cerámica oriental (Bonsor 1997 [1899]: 85; figs. 83, 84, 86, 87 y 88), mientras que a las digitadas les daba un origen indígena (Bonsor 1997 [1899]: 82; figs. 70, 52, 55 y 58).

Medio siglo más tarde, Esteve, durante las excavaciones de Asta Regia, también encontró algunos fragmentos sobre todo de cerámicas bruñidas y grabadas, atribuyendo su origen, siguiendo a Santa Olalla, al Bronce Mediterráneo I (Esteve 1950:30). Como se desprende de un texto de Aubet (1992:37) en aquellos momentos, las décadas de los cuarenta y cincuenta del siglo XX, el escepticismo y la desesperación por encontrar algún vestigio material de la legendaria cultura tartésica habían hecho mella en el ánimo de los investigadores. Por otro lado la figura de Schulten aún estaba muy presente en las mentes de los investigadores, quienes siguiendo el ejemplo del erudito alemán, se afanaban por localizar la grandiosa ciudad de Tartessos.

Pero no pasaría mucho tiempo hasta que, en 1958, El Carambolo dibujase una línea divisoria en la historia de la investigación de la protohistoria del suroeste andaluz. El tesoro, que en aquel momento se pensó digno del mismísimo Argantonio, causó tal impacto en las mentes de sus excavadores que condicionó el resto de los hallazgos, hasta el punto de que aún no había comenzado la excavación propiamente dicha, y ya se sabía que lo que se habría de desenterrar eran restos de la cultura tartésica. No sólo el clima científico 
fue una circunstancia determinante, también el ambiente político de la época influyó en la interpretación. Si analizamos con atención los artículos de prensa referentes al descubrimiento del tesoro, podemos leer entre líneas la fuerza que tiene el sentimiento de búsqueda de la identidad nacional y las raíces del pueblo andaluz, al cual, sin lugar a dudas, se atribuyeron aquellos dorados vestigios.

Indudablemente en el plano de la cerámica las protagonistas del momento fueron las pintadas Tipo Carambolo y las de retícula bruñida, tipos 18 y 17 de la clasificación de Carriazo (1973:484 y ss). Además de estos tipos en El Carambolo se recogieron gran cantidad de materiales a torno de origen claramente oriental, cuyo repertorio comenzaba a conocerse también por aquellos entonces. Los tipos 17 y 18 no se contaban entre las cerámicas conocidas como fenicias y además estaban fabricadas a mano, se consideraron claramente indígenas.

En los años que transcurrieron entre el final de la excavación y la publicación del libro de Carriazo, la, por fin, cerámica tartésica se documentó en otros yacimientos como Carmona (Carriazo y Raddatz 1960) y Huelva (Blázquez y otros 1970). El impacto causado por estas dos especies, tanto por el elevado número de ejemplares que aportó El Carambolo como por lo novedoso y espectacular de sus decoraciones, hizo que los especialistas se centraran rápidamente en ellas. Desde entonces la mayoría de estudios sobre el repertorio cerámico tartésico se han centrado sobre todo en dos de estas familias, las decoradas con motivos geométricos bruñidos y las pintadas Tipo Carambolo o Guadalquivir I, sin haber entrado a revisar en profundidad el método usado para llegar a aquellas conclusiones.

\section{UN BREVE RECORRIDO POR LA BIBLIOGRAFÍA}

La cerámica con decoración grabada ha pasado siempre muy silenciosamente por la bibliografía que versa sobre Tartessos en general, y la que trata sobre su cultura material en particular. Existe una serie de trabajos que intentan clasificar de una manera general los diferentes tipos cerámicos que componen el repertorio vascular tartésico (Almagro 1977; Ruiz Mata 1980; Ruiz Mata 1995; Murillo 1994:235 y ss). Cuando en estos trabajos se hace alguna referencia a las decoraciones, por norma general solo se mencionan las de motivos geométricos bruñidos (Ruiz Mata 1995: 289, Fig.5), las pintadas Tipo Carambolo (Murillo 1994:316 y ss) y las de superficies toscas con motivos incisos e impresiones digitales (Ruiz Mata 1995: 309, fig.25). Este último tipo, aunque tratado como parte de la vajilla tartésica en obras de conjunto sobre ésta (p.e. Blanco y otros 1969), solo ha sido objeto de un estudio monográfico por parte de Ladrón de Guevara (1994).

Por norma general, la escasa representación, tanto en los yacimientos en sí (fig. 1) como en número de individuos dentro de éstos, que tiene la cerámica grabada en los asentamientos del Bronce Final/Hierro I, puede ser la causa de que los excavadores le presten poca atención a la hora de elaborar sus informes. Si aparece algún fragmento en el yacimiento, la información vertida sobre él y la cerámica grabada en general no suele pasar de la mera descripción y el dibujo de la pieza. Si se hace algún breve comentario es para comparar sus motivos decorativos con los de la Tipo Carambolo (Pellicer y Hurtado 1986:339).

La primera aparición de la cerámica grabada en la bibliografía se remonta a las excavaciones de Asta Regia, donde Esteve presenta un fragmento, junto con otros materiales, en la lámina $\mathrm{V}$, y que atribuye al Bronce Mediterráneo I, concretamente a una población de cultura ibero-sahariana (Esteve 1950:30). Posteriormente Leisner vuelve a citar los materiales hallados por Esteve en su figura 8 (Leisner 1961:Fig. $7, n^{\circ} 8$ ). Algunos años más tarde, durante las primeras excavaciones del Cabezo de San Pedro, en Huelva, los autores recogen un curioso fragmento de cerámica grabada con una representación de procesión de aves (Blázquez y otros 1970: lám. XXIX), cuyas líneas de grabado presentan restos de haber sido rellenas con pasta de color rojo. Ponen en relación las procesiones de aves con el mundo celtibérico y la Galaecia 
durante la Edad del Hierro (Blázquez y otros 1970:16). Aunque en estudios posteriores se ha podido ver cómo las procesiones de aves son un tema bastante recurrente no solo dentro de la cerámica Tipo Carambolo (Buero 1984), sino en la iconografía oriental, por ejemplo en Chipre (Karageorgis 1974:272 y ss.). Este fragmento es bastante peculiar, porque junto con otro que tiene grabado un grifo (Blázquez y otros 1979: 31), son los dos únicos que, hasta la fecha, presentan representaciones zoomorfas (fig.2). El Cabezo de San Pedro aportará algunos fragmentos más que se verán recogidos en publicaciones posteriores (Blázquez y otros 1979; Del Amo y Belén 1981).

En 1973 Carriazo publica su voluminosa obra sobre El Carambolo en la que, aunque ya había adelantado datos en otras publicaciones anteriores, trata con mayor profundidad el conjunto de las cerámicas que recogió en la excavación tanto del Carambolo alto como del poblado bajo. Esta obra, en cuanto a lo que cerámicas a mano se refiere, centraría, como dijimos anteriormente, su atención en las pintadas Tipo Carambolo y las decoradas con motivos bruñidos, considerando ambas como las genuinas representantes de la vajilla tartésica (Carriazo 1973: 484 y 504). Pero ante la espectacularidad numérica de sus hermanas pasaron desapercibidos algunos fragmentos decorados con motivos geométricos grabados (Carriazo 1973:543 y 565), sobre los que, aparte de los comentarios de las fotos, no aparece más información. En estos pies de foto podemos ver que Carriazo se refiere a la decoración de triángulos tramados como derivada del campaniforme, mientras que los otros simplemente son "pequeños vasos con excepcional decoración grabada" (Carriazo 1973: 543).

Algunos años después de la obra de Carriazo y mientras se sucedían los estudios sobre la decoración bruñida, encontramos tres fragmentos de cerámica grabada en el informe preliminar de la campaña de 1976 en Morro de Mezquitilla (Schubart 1979:202 y lám. VII). Estas piezas proceden según el excavador de estratos fenicios. No olvidemos que Morro de Mezquitilla ha sido considerado siempre una colonia de dicha etnia.

La excepción a la regla se registra en el yacimiento de Acinipo, en Ronda la Vieja, Málaga. En este yacimiento se registra, sobre el nivel de hiato, un grupo de cerámicas con decoraciones de líneas y motivos geométricos grabados que mantendrá su presencia a lo largo de toda la secuencia estratigráfica, "constituyendo un grupo de cerámicas muy característicos de este poblado", en palabras textuales del autor (Aguayo y otros 1985:299). Realmente este es un dato interesante ya que en ningún otro yacimiento excavado hasta la fecha, perteneciente a este arco cronológico, se puede decir que la cerámica grabada sea tan abundante que se convierta en característica del yacimiento. Salvo las dos imágenes que publica J. A. Martín Ruiz (1995:224; fig. 230) no conocemos más fotos ni dibujos publicados en la bibliografía especializada.

En los años siguientes se registran en la bibliografía algunas noticias de hallazgos de cerámicas grabadas en diversos yacimientos del área sevillana como Montemolín (Chaves y De la Bandera 1984: 152; De la Bandera 1993:17) y El Gandul (Pellicer y Hurtado 1986), sin aportar mayores datos ni interpretaciones sobre la cerámica objeto de nuestro estudio.

Nos interesa destacar los casos de la provincia de Cádiz ya que registran una gran presencia de cerámica grabada y aportan, como veremos, datos de gran interés para intentar comprender la funcionalidad de la misma.

En 1986 Ruiz Mata publica algunos fragmentos hallados en El Castillo de Doña Blanca(Ruiz Mata 1986: Fig. $3, n^{\circ} 37$, Fig. $4 n^{\circ} 32$ ), yacimiento que por aquel entonces su excavador aún consideraba una fundación tartésica (Ruiz Mata 1986: fig.1), ya que como señala en dicho artículo las cerámicas a mano de tradición indígena constituían el porcentaje mayor (Ruiz Mata 1986: 548). Al yacimiento de Doña Blanca pertenecen también algunos fragmentos presentados por K. Mansel (Mansel 1998: lám 2 y 3). La autora pone en relación este tipo cerámico con otros similares recogidos en yacimientos de la costa de África, sobre todo Cartago y Lixus. Sobre este particular trataremos más adelante.

Pero los datos más interesantes los aportará la necrópolis de Las Cumbres, asociada al yacimiento anteriormente mencionado de Doña Blanca. El túmulo 1, conjunto funerario compuesto por más de 60 incineraciones, ofrece una tipología de urnas muy variada y entre las cuales podemos identificar ollas de superficies bruñidas y decoradas con motivos grabados y con el interior pintado de almagra (Ruiz Mata y Pérez 1989:291). 
Pertenecen, según los autores, a los enterramientos más antiguos, datados en la primera mitad del s. VIII a.C. (Ruiz Mata y Pérez 1989:292). También relativos al mundo funerario son los testimonios recogidos en superficie en Asta Regia (Jerez de la Frontera), de nuevo en la provincia de Cádiz. Con los datos aportados por las prospecciones superficiales de 1992 (González Rodríguez y otros 1995: 217) se identificó una zona de necrópolis a espaldas del núcleo principal de hábitat del yacimiento. Entre los materiales hallados se pueden contar varios fragmentos de cazuelas carenadas con decoración de motivos geométricos grabados (González Rodríguez y otros 1995: Lám. 2, nº 10 y 11; foto 2). Los autores del artículo hacen una apreciación acerca de esta cerámica y comentan que, dada la frecuencia con la que aparece en el área gaditana, cabría la posibilidad de pensar que fuese una especie propia de dicha zona (González Rodríguez y otros 1995:219), más adelante incidiremos sobre este aspecto. Otros yacimientos de la zona gaditana aportan fragmentos de cerámica grabada como son el de las Beatillas (Ruiz Gil y otros 1990:19), Vejer de la Frontera (Molina Carrión 1991:102), Pocito Chico (Puerto de Santa María) (Ruiz Gil y López Amador 2001: 56, 132 y 133; Láms. 28 y 29), El Berrueco (Medina Sidonia) (Escacena y otros 1998: 11).

En la provincia de Córdoba se registran también algunos testimonios como los recogidos en superficie (Godoy y Morena 1989:125) y por Murillo, en la colina de los Quemados (Murillo1994:210). Este último las llama esgrafiadas y las sitúa en la fase III del yacimiento, poniéndolas en relación con las otras especies cerámicas del Bronce Final Tartésico.

Para terminar, habría que destacar un último trabajo publicado en 1998 por Escacena, del Río y Luna, que hasta el momento es la única referencia bibliográfica que se centra totalmente en la cerámica grabada. Los autores dan a conocer dos testimonios procedentes del Cerro Mariana ( Las Cabezas de San Juan, Sevilla) y del Berrueco (Medina Sidonia, Cádiz) (Escacena y otros 1998). En este trabajo no solo se hace una descripción exhaustiva de los fragmentos, sino además una exposición general sobre los aspectos más importantes que caracterizan a la cerámica grabada. El trabajo también pone de manifiesto el desconocimiento que se tiene dentro del panorama científico acerca de este tipo cerámico (Escacena y otros 1998: 9 y ss.).

\section{NOTAS SOBRE LA CERÁMICA GRABADA}

Como adelantábamos, dentro del conjunto vascular tartésico la cerámica grabada pertenecería al grupo de vajilla fina, ya que presenta el acabado de la superficie mediante la técnica del bruñido. La decoración de motivos grabados se realiza siempre posteriormente a la cocción del recipiente. Por este motivo debemos emplear el término grabado y no incisión, que se referiría a decoraciones realizadas con el barro aún fresco, como el caso de los recipientes de superficies toscas. Entre los autores que han mencionado esta especie cerámica no existe unanimidad a la hora de referirse a ella como grabada (Chaves y De la Bandera 1984:152; Aguayo y otros 1985: 299; Escacena y otros 1998) o incisa (González y otros 1995: 215; De la Bandera 1993: 17; Ruiz Mata y otros 1981: 246; Ruiz Mata 1986:545; Ruiz Mata y Pérez 1989:291).

Muchas veces encontramos que el dibujo realizado mediante grabado está, además, relleno de pasta roja para realzar el motivo y dar un mejor acabado a la decoración (Blázquez y otros 1970:16; Bandera, de la 1993: 17; Ruiz Gil y otros 1990:19; Ruiz Mata y otros 1981:246).

Las formas elegidas para plasmar esta decoración suelen estar siempre dentro de cazuelas y cuencos carenados de superficies previamente bruñidas, aunque también puede encontrarse en soportes de carrete (Schubart 1979: lám. VII).

Generalmente los motivos que decoran nuestra cerámica son geométricos, salvo los dos casos de zoomorfos anteriormente citados. Entre las composiciones geométricas que observamos podemos reconocer algunos motivos que abundan también en su pariente pintada, la Tipo Carambolo. Algunos de estos recursos comunes 
son muy sencillos y los encontramos en cerámicas de otras cronologías y áreas geográficas, como el caso de las sucesiones de triángulos tramados, pero otros repiten composiciones de mayor complejidad (fig. 3).

En cuanto al área de dispersión, vemos que, aunque de manera más discreta que otros tipos cerámicos de su familia, se reparte por lo que se ha venido considerando el territorio tartésico. Aunque también podemos encontrarla fuera de los límites clásicos de Tartessos, se ha documentado cerámica grabada en colonias fenicias de la costa africana, concretamente en Lixus (Bokbot 1998) y Cartago (Mansel 1998). Como ya se había referido anteriormente, y puede observarse en el mapa de la figura 1 , se aprecia una mayor presencia de cerámica grabada en el área de Cádiz. Ante esta observación se ha sugerido que la especie cerámica que aquí tratamos sea característica de dicha zona (González Rodríguez y otros 1995:219); pero, como más de una vez se ha demostrado en la historia de las investigaciones, el lugar donde las cosas aparecen en más cantidad, o lo hacen por primera vez, no tiene por qué ser su zona de origen (Escacena 2000:59 y ss). Las posibles zonas de producción y vías de redistribución de esta cerámica solo podrán llegar a conocerse mediante análisis y comparación de pastas.

En muchas ocasiones los fragmentos de cerámica grabada aparecen estratificados (Blázquez y otros 1970:13; Blázquez 1979:31; Aguayo y otros 1985:299; Ruiz Mata y Pérez 1989:292; Chaves y De la Bandera 1984:153), por lo que es relativamente fácil colocarla dentro del marco cronológico que comparte con el resto de las cerámicas bruñidas tartésicas, siempre entre los siglos VIII y VI a.C.

Las numerosas concomitancias, en cuanto a formas y decoraciones, entre la cerámica grabada y la pintada Tipo Carambolo, así como lo inusual de ambos tipos, nos hace ponerlas en relación casi de manera automática. Sin duda la cerámica que aquí se analiza no debía tener un uso como vajilla de mesa o cocina por el cuidado que se pone en su elaboración y la escasez con la que aparece. El hecho de que en el área de Cádiz se haya documentado cerámica grabada realizando función de contenedor funerario (Ruiz Mata y Pérez 1989: 291, González Rodríguez y otros 1995:219) nos proporciona datos acerca de su utilización con fines sacros, aunque por el momento los datos son escasos para deducir un uso exclusivo con fines funerarios o rituales de otro tipo. No debemos olvidar que los yacimientos donde se encuentran en un número más elevado de ejemplares como Acinipo o Doña Blanca no han dado muestras, hasta el momento, de contener recintos sagrados de tipo templario. Tampoco hay que perder de vista el hecho de que en otras ocasiones se han documentado ánforas y otros tipos de contenedores de ámbito doméstico cumpliendo la función de urna cineraria, sin que éste sea en fin concreto para el que se fabricó.

\section{CONSIDERACIONES FINALES}

Ruiz Mata expone en un reciente trabajo la siguiente reflexión y con la que sin duda estamos de acuerdo "Siempre es saludable abordar viejos problemas con nuevas premisas. Las verdades infundadas, o dudosas, contribuyen a crear una cadena sustentada en un nódulo poco consistente, y así girando sucesivamente en una rueda sin fin." (Ruiz Mata 1999: 280). A lo largo de este trabajo hemos intentado seguir la pista por la bibliografía a la cerámica grabada y mostrar de manera general cuál ha sido y es su papel en el desarrollo de las investigaciones sobre la cultura material tartésica. En el primer apartado se ha procurado ofrecer de manera concisa los pasos que, a nuestro entender, dio la investigación para alcanzar el estado actual, en lo que al mundo de la cerámica tartésica se refiere. El estudio de la protohistoria del suroeste peninsular, especialmente el tránsito Bronce Final- Hierro I, se encuentra en un punto de inflexión. Decimos esto porque ciertos sectores de la comunidad científica dedicada a este período están comenzando a arrojar nuevas hipótesis de trabajo y revisar antiguos postulados. Estas nuevas líneas de investigación conducen, por ejemplo, a la reinterpretación de yacimientos emblemáticos de la cultura tartésica como asentamientos fenicios, como es el caso del Carambolo (Belén y Escacena 1998) o el de Doña Blanca, que también pasó de ser fundado 
por tartesios (Ruiz Mata 1986) a ser colonia fenicia (Ruiz Mata 1999). Debemos tener en cuenta que, aunque haya cambiado la etnicidad, al menos para nosotros, de los yacimientos, los materiales que nos han conducido a ambas interpretaciones siguen siendo los mismos, lo único que ha cambiado son las circunstancias, volviendo a la frase con la que abríamos el trabajo.

También se están empezando a abandonar otras férreas convicciones como la de situar a los fenicios en la costa y a los indígenas al interior, o la de pensar que los fenicios solo usaban cerámica a torno y por lo tanto toda vasija hecha a mano debía pertenecer a los indígenas.

Ante este panorama cambiante, y que aún ha de ser lentamente digerido por la comunidad científica, nos gustaría plantear una serie de cuestiones. Si un yacimiento que sentó las bases para caracterizar la vajilla tartésica, ahora es considerado fenicio, ¿cómo afecta eso a la cerámica?, si reconocemos que fenicios e indígenas pueden asentarse en el interior o en la costa indistintamente, y en ambos tipos de yacimientos encontramos los mismos materiales, ¿cómo diferenciar unos de otros? y nuevamente, ¿cómo afecta esto a la lectura de los materiales?.

El mundo de la cerámica tartésica puede ser una de esas viejas verdades a las que se refiere Ruiz Mata y se encuentra aún muy lejos de estar claramente definido. Se debe profundizar, sin perder de vista cuestiones como las arriba expuestas, en el estudio de especies cerámicas que como la grabada por su carácter especial y el posible contenido simbólico de sus motivos decorativos puedan aportar un poco de luz a este período aún tan oscuro de nuestra historia y nos ayuden a dejar de girar "sucesivamente en una rueda sin fin".

\section{BIBLIOGRAFÍA}

AGUAYO, P.; CARRILERO, M.; DE LA TORRE, Ma del P. y FLORES, C. (1985): "El yacimiento pre y protohistórico de Acinipo (Ronda, Málaga). Campaña de 1985", Anuario Arqueológico de Andalucía/ 1985, II Actividades Sistemáticas: 294-304. Sevilla, Consejería de Cultura.

ALMAGRO-GORBEA, M. (1977): El Bronce Final y el Periodo Orientalizante en Extremadura. (Bibliotheca Praehistorica Hispana, XIV). Madrid. Consejo Superior de Investigaciones Científicas.

AUBET, M.E. (1992): "Maluquer y la renovación de la arqueología tartésica", Clásicos de la Arqueología de Huelva 5. Diputación Provincial de Huelva.

BELÉN, M. y ESCACENA, J. L. (1998): "Testimonios religiosos de la presencia fenicia en Andalucía occidental”, en El Mediterráneo en la Antigüedad: Oriente y Occidente (Cunchillos y otros eds.) Sapanu. Publicaciones en Internet II, http://www.labherm.csic.es.

BLANCO, A.; LUZÓN, J. M. y RUIZ MATA, D. (1969): "Panorama tartésico en Andalucía oriental”, Tartessos y sus problemas. V Symposium Internacional de Prehistoria Peninsular (Jerez de la Frontera, 1968): 119-162. Barcelona, Universidad de Barcelona.

BLÁZQUEZ, J. M.; LUZÓN, J. M.; GÓMEZ, F. y CLAUSS, K. (1970): “Las cerámicas del Cabezo de San Pedro", Huelva Arqueológica I. Huelva.

BLÁZQUEZ, J. M.; RUIZ MATA, D.; REMESAL, J.; RAMÍREZ SADABA, J. L. y CLAUSS, K. (1979): Excavaciones en el Cabezo de San Pedro (Huelva). Campaña de 1977 (Excavaciones Arqueológicas en España 102). Madrid, Ministerio de Cultura.

BOKBOT, Y. (1998): "Une céramique à graffito à Lixus", Bulletin d'archeologie Marrocaine, Tome XVIII: 321-323.

BONSOR, G. (1997 [1899]): Las colonias agrícolas prerromanas del valle del Guadalquivir. Sevilla, Gráficas Sol.

BUERO, M. S. (1984): "Los motivos naturalistas en la cerámica pintada del Bronce Final del Suroeste peninsular", Habis 15: 345-364. 
CARRIAZO, J. de M.(1973): Tartessos y El Carambolo. Madrid, Patronato Nacional de Museos.

CARRIAZO, J. de M. y RADDATZ, K. (1960): "Primicias de un corte estratigráfico en Carmona", Archivo Hispalense, $2^{\mathrm{a}}$ época, XXXIII, $\mathrm{n}^{\circ}$ 103-104: 333-369.

CHAVES, F. y DELA BANDERA, M. L. (1984): “Avance sobre el yacimiento arqueológico de Montemolín (Marchena, Sevilla)" en Papers in Iberian Archaeology (BAR International Series 193): 141-186. Oxford.

DELA BANDERA, M. L.; CHAVES, F.; ORIA, M.; FERRER, E.; GARCÍA VARGAS, E. y MANCEBO,

J. (1993): "Montemolín. Evolución del asentamiento durante el Bronce Final y el período orientalizante (Campaña de 1980 y 1981)" Anales de Arqueología Cordobesa 4: 15-48.

DEL AMO, M. y BELÉN, M. (1981): "Estudio de un corte estratigráfico en el Cabezo de San Pedro", Huelva Arqueológica, V: 57-148.

ESCACENA, J. L.; DEL RÍO, A. y LUNA, M. A. (1998): "Cerámica tartésica con decoración grabada. Nuevos testimonios", Anales de Arqueología Cordobesa 9: 9-23.

ESTEVE, M. (1950): Excavaciones en Asta Regia (Mesas de Asta, Jerez). Campaña 1945-46. (Informes y Memorias de la Comisaría General de Excavaciones Arqueológicas 22). Madrid. Ministerio de Educación Nacional.

GODOY, F. y MORENA, J. A. (1989): "Prospección arqueológica superficial de urgencia en los terrenos afectados por la red de distribución de gas natural e industrias en Córdoba" Anuario Arqueológico de Andalucía / 1989 III, Actividades de Urgencia: 119-126. Sevilla, Consejería de Cultura.

GONZÁLEZ RODRÍGUEZ, R.; BARRIONUEVO, F. y AGUILAR, L. (1995): “Mesas de Asta, un centro indígena tartésico en los esteros del Guadalquivir" Tartessos, 25 años después 1968-1993. Jerez de la Frontera. Ayuntamiento de Jerez de la Frontera.

KARAGEORGIS, V. (1974) La céramique chypriote de style figure. Âge du Fer (1050-500 av. J.C). Ilustrations et descriptions des vases. Roma.

LADRÓN DE GUEVARA, I. (1994): Aportación al Estudio de la Cerámica con Impresiones Digitales en Andalucía. Cádiz, Universidad de Cádiz.

LEISNER, V. (1961): "Imenverzierte schalen der Kupferzeit auf der Iberischen Halbinsel", Madrider Mitteilungen, 2: 11-34.

MANSEL, K. (1998): "Verzierte handgemachte Keramik des 8. Und 7. Jhs. V. Chr. Aus Karthago. Ein Beitrag zur Keramik nichtpunnischer Tradition" Veröff. Joachim Jugius-Ges. Wiss. Hamburg, 87: 559-571.

MARTÍN RUIZ, J. A. (1995): Catálogo documental de los fenicios en Andalucía (Aubet, M. E. Dir.). Sevilla, Consejería de Cultura.

MOLINA, M. (1991): "Informe de la excavación de urgencia en la Iglesia Mayor de las Monjas concepcionistas (Vejer de la Frontera, Cádiz)" Anuario Arqueológico de Andalucía/1991, III, Actividades de Urgencia: 94-107. Sevilla, Consejería de Cultura.

MURILLO, J. F. (1994): La Cultura Tartésica en el Guadalquivir Medio, en Ariadna 13-14. Palma del Río, Museo Municipal.

PELLICER, M. y HURTADO, V. (1986): "Excavaciones en la Mesa del Gandul (Alcalá de Guadaira, Sevilla)", Anuario Arqueológico de Andalucía /1986 II, Actividades Sistemáticas: 338-341. Sevilla, Consejería de Cultura.

PELLICER, M. (1987-88): “La cerámica a mano del Bronce Reciente y del Orientalizante en Andalucía occidental", Habis 18-19:461-483.

_- (1989): "El Bronce Reciente y los inicios del Hierro en Andalucía occidental", en Ma. E. Aubet (coord..), Tartessos. Arqueología Protohistórica del Bajo Guadalquivir. 147-187. Sabadell, Ausa.

RUIZ GIL, J. A.; PÉREZ FERNÁNDEZ, F.; LÓPEZ AMADOR, J. J. y MONCLOA, A. (1990): "El yacimiento protohistórico de las Beatillas (El Puerto de Santa María)", Revista de Estudios de El Puerto 4: 11-38. 
RUIZ GIL, J. A. y LÓPEZ AMADOR, J. J. (2001): Formaciones sociales agropecuarias en la Bahía de Cádiz. 5000 años de adaptación ecológica en la Laguna del Gallo, El Puerto de Santa María. Cádiz, Arqueodesarrollo Gaditano.

RUIZ MATA, D. (1980): "El Bronce Final -fase inicial- en Andalucía Occidental. Ensayo de definición de sus cerámicas", Archivo Español de Arqueología LII: 3-15.

(1986): "Aportación al análisis de los indicios de la presencia fenicia en Andalucía suroccidental, según las excavaciones del Cabezo de San Pedro (Huelva), San Bartolomé (Almonte, Huelva), Castillo de Doña Blanca (Puerto de Santa María, Cádiz) y el Carambolo (Camas, Sevilla)", en Homenaje a Luis Siret (1934-1984):537-556. Sevilla, Consejería de Cultura.

(1995): "Las cerámicas del Bronce Final. Un soporte tipológico para delimitar el tiempo y el espacio tartésico", Tartessos, 25 años después 1968-1993. Jerez de la Frontera, Ayuntamiento de Jerez de la Frontera.

(1999): "La fundación de Gadir y el Castillo de Doña Blanca: contrastación textual y arqueológica", Complutum 10: 279-317.

RUIZ MATA, D. y PÉREZ, C. (1989): “El túmulo 1 de la necrópolis de «Las Cumbres» (Puerto de Santa María, Cádiz)”, en Aubet, M. E. (coord.) Tartessos. Arqueología Protohistórica del Bajo Guadalquivir. Sabadell, Ausa.

SCHUBART, H. (1976): "Morro de Mezquitilla, informe preliminar sobre la campaña de excavaciones de 1976", Noticiario Arqueológico Hispánico 6: 175-207. 


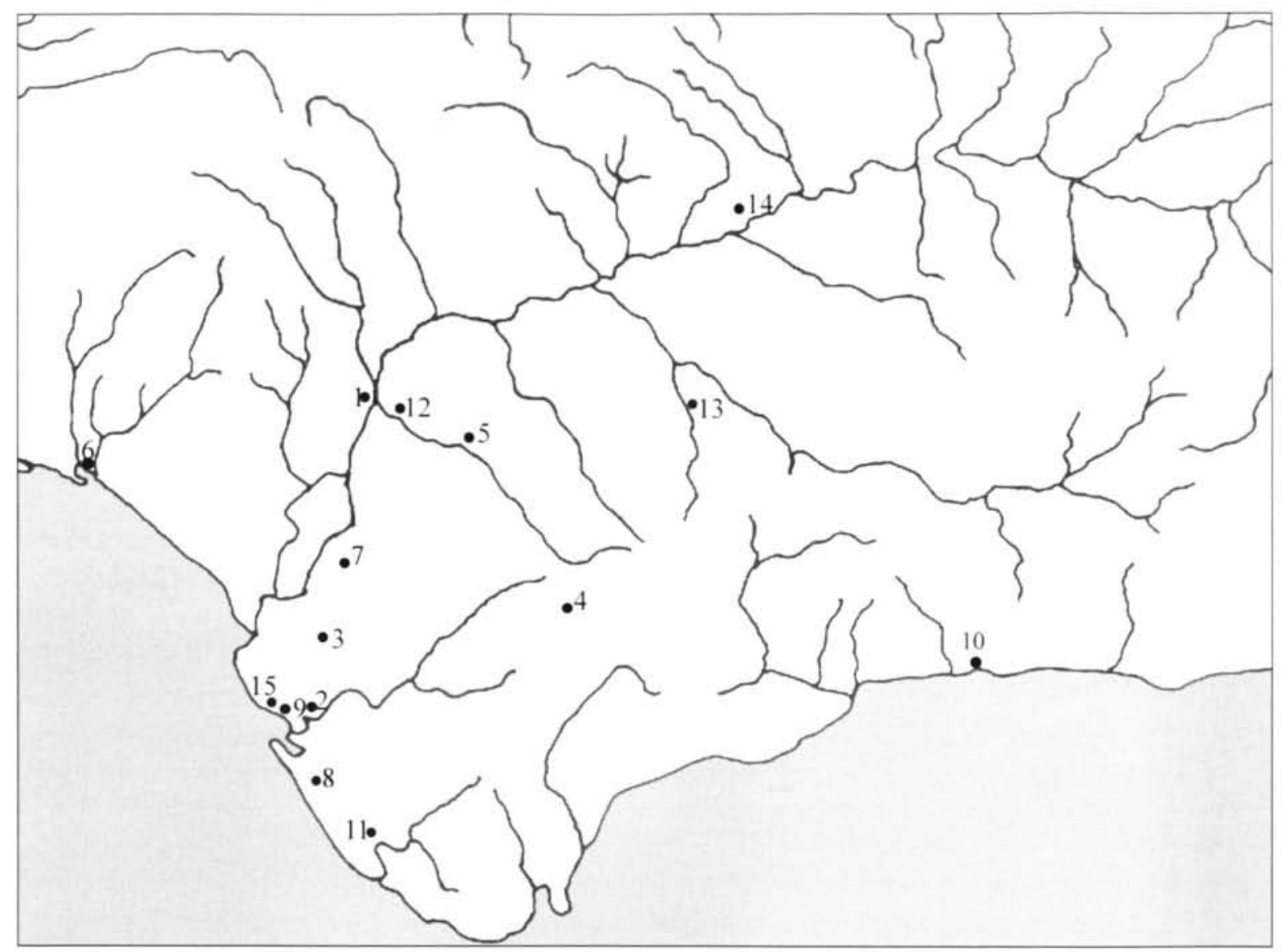

Figura 1. Yacimientos de época tartésica del suroeste peninsular, citados en el texto, donde se ha documentado cerámica grabada. 1.-El Carambolo, 2.- Doña Blanca, 3.-Asta Regia, 4.- Acinipo, 5.- Montemolín, 6.-Huelva, 7.- Las Cabezas de San Juan, 8.- El Berrueco, 9.- Las Beatillas, 10.-Morro de Mezquitilla, 11.- Vejer de la Frontera, 12.- El Gandul, 13.- Estepa, 14.- Colina de los Quemados, 15.- Pocito Chico. 


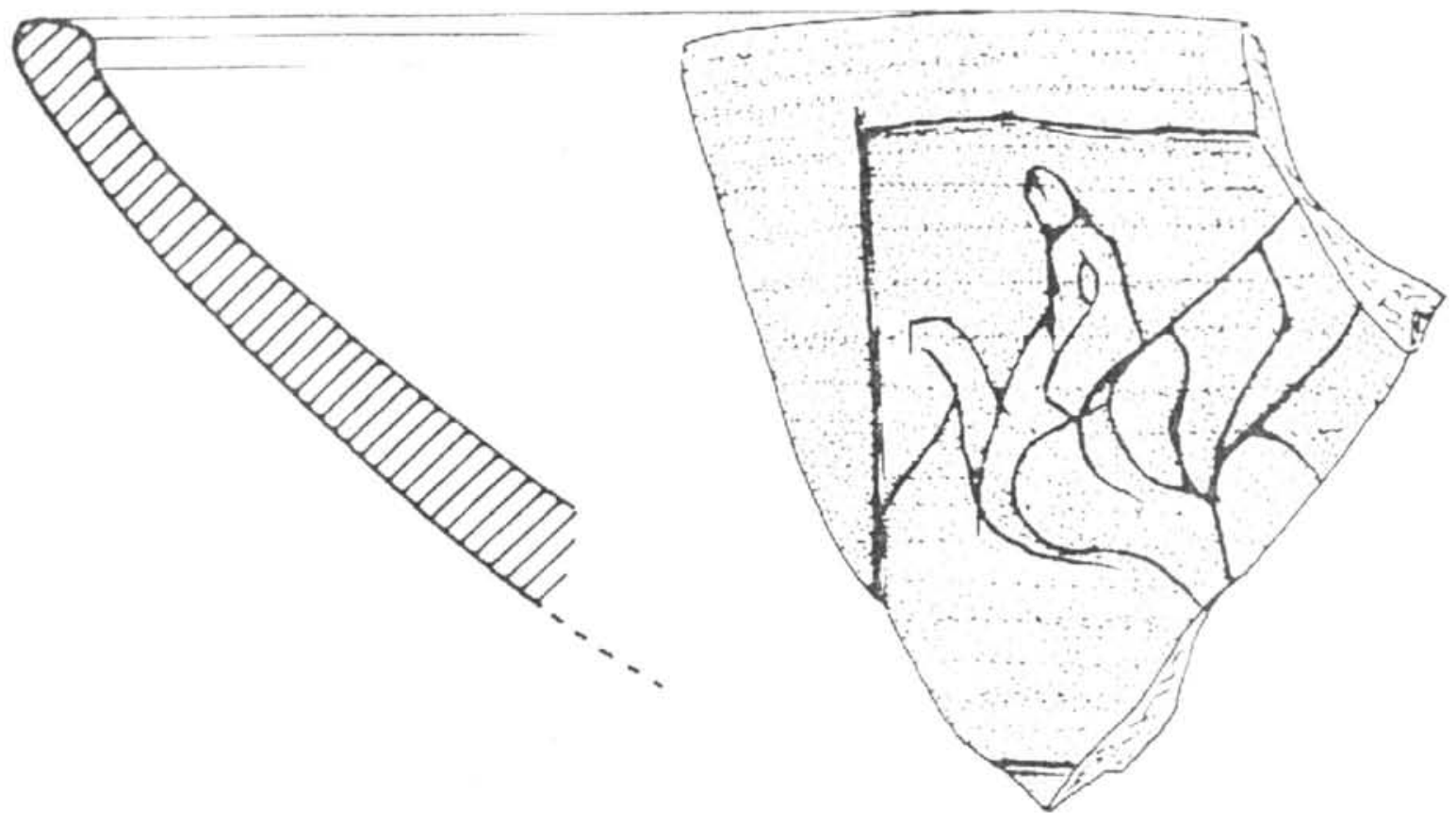

Figura 2. Fragmento de cerámica grabada con decoración zoomorfa. Blázquez y otros 1979.
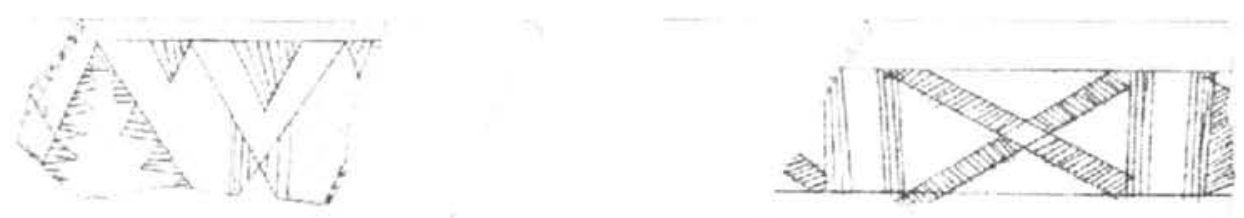

Figura 3. Detalle de composiciones geométricas grabadas. Escacena y otros 1998. 